\title{
Clinical correlates of blood-derived circulating tumor DNA in pancreatic cancer
}

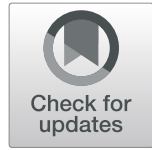

\author{
Hitendra Patel ${ }^{1 \dagger}$, Ryosuke Okamura ${ }^{1 *} \mathbb{B}$, Paul Fanta ${ }^{1}$, Charmi Patel ${ }^{2}$, Richard B. Lanman ${ }^{3}$, Victoria M. Raymond ${ }^{3}$, \\ Shumei Kato ${ }^{1}$ and Razelle Kurzrock ${ }^{1}$
}

\begin{abstract}
Background: Treatment outcomes for patients with advanced pancreatic ductal adenocarcinoma (PDAC) remain dismal. There are unmet needs for understanding the biologic basis of this malignancy using novel next-generation sequencing technologies. Herein, we investigated the clinical utility of circulating tumor DNA (ctDNA) (the liquid biopsy) in this malignancy.

Methods: ctDNA was analyzed in 112 patients with PDAC (54-73 genes) and tissue DNA in 66 patients (315 genes) (both clinical-grade next-generation sequencing). Number of alterations, \%ctDNA, concordance between ctDNA and tissue DNA, and correlation of ctDNA results with survival were assessed.

Results: The most common genes altered in ctDNA were TP53 (46\% of patients, $N=51$ ) and KRAS (44\%, $N=49$ ). Median number of characterized ctDNA alterations per patient was 1 (range, 0-6), but patients with advanced PDAC had significantly higher numbers of ctDNA alterations than those with surgically resectable disease (median, 2 versus $0.5, P=0.04)$. Overall, $75 \%$ (70/94) of advanced tumors had $\geq 1$ ctDNA alteration. Concordance rate between ctDNA and tissue DNA alterations was $61 \%$ for TP53 and 52\% for KRAS. Concordance for KRAS alterations between ctDNA and tissue DNA from metastatic sites was significantly higher than between ctDNA and primary tumor DNA (72\% vs 39\%, $P=0.01$ ). Importantly, higher levels of total \%ctDNA were an independent prognostic factor for worse survival (hazard ratio, 4.35; 95\% confidence interval, 1.85-10.24 [multivariate, $P=0.001$ ]). A patient with three ctDNA alterations affecting the MEK pathway (GNAS, KRAS, and NF1) attained a response to trametinib monotherapy ongoing at 6 months.
\end{abstract}

Conclusions: Our findings showed that ctDNA often harbored unique alterations some of which may be targetable and that significantly greater numbers of ctDNA alterations occur in advanced versus resectable disease. Furthermore, higher ctDNA levels were a poor prognostic factor for survival.

Keywords: Pancreatic cancer, Next-generation sequencing, Circulating tumor DNA, KRAS, Molecular oncology, Targeted therapy

\section{Introduction}

In the USA, there are approximately 56,770 people newly diagnosed with pancreatic cancer in 2019, with high mortality $(\sim 46,000$ deaths $)[1-3]$.Although the mortality from other types of gastrointestinal cancer, such as gastric or colorectal cancers, are declining over the past two decades, mortality from pancreatic cancer

\footnotetext{
* Correspondence: ryokamura@ucsd.edu

${ }^{+}$Hitendra Patel and Ryosuke Okamura contributed equally to this work.

${ }^{1}$ Center for Personalized Cancer Therapy and Division of Hematology and Oncology, Department of Medicine, UC San Diego Moores Cancer Center, 3855 Health Sciences Drive, La Jolla, CA 92093, USA

Full list of author information is available at the end of the article
}

has not declined [1]. It is estimated that pancreatic cancer will become the second cause of cancer death by 2030 [2].

The majority of pancreatic cancers (80-90\%) are classified as pancreatic ductal adenocarcinomas (PDACs) [3]. One of the underlying reasons for high mortality associated with PDACs is that most patients have late-stage disease at the time of diagnosis. In fact, only $15-20 \%$ of patients are considered to be surgical candidates at the diagnosis [4]. Furthermore, prognosis even among patients who were able to have surgery with negative margins

(c) The Author(s). 2019 Open Access This article is distributed under the terms of the Creative Commons Attribution 4.0 International License (http://creativecommons.org/licenses/by/4.0/), which permits unrestricted use, distribution, and reproduction in any medium, provided you give appropriate credit to the original author(s) and the source, provide a link to the Creative Commons license, and indicate if changes were made. The Creative Commons Public Domain Dedication waiver (http://creativecommons.org/publicdomain/zero/1.0/) applies to the data made available in this article, unless otherwise stated. 
remains poor (5-year survival rate was only $10-25 \%$ with the median survival between 10-20 months) [5, 6].

Multi-agent systemic chemotherapies with regimens of 5-fluorouracil, leucovorin, irinotecan, and oxaliplatin (FOLFIRINOX) and gemcitabine plus nab-paclitaxel have shown improved survival over single-agent gemcitabine and have become standard treatment options for metastatic PDACs $[7,8]$. However, median progressionfree survival (PFS) and overall survival (OS) remain dismal (PFS: FOLFIRINOX, 6.4 months; gemcitabine plus nab-paclitaxel, 5.5 months, gemcitabine alone, 3.3-3.7 months; OS: FOLFIRINOX, 11.1 months; gemcitabine plus nab-paclitaxel, 8.5 months, gemcitabine alone, 6.76.8 months) $[7,8]$. Therefore, along with the recent development in sequencing technology, a personalized, molecular-targeted approach for PDAC is becoming an active area of research [9]. Several case studies showed a benefit of platinum-based chemotherapies or poly ADPribose polymerase (PARP) inhibitors for PDAC patients with $B R C A 1 / 2$ abnormalities, and the NCCN guidelines suggest consideration of platinum-based regimen as a first-line therapy for advanced-stage pancreatic cancer patients with BRCA gene mutations [10-14].

Although molecular analysis on tissue samples is generally attempted, its clinical utility is often diminished in pancreatic cancer due to the difficulty in obtaining tissue with adequate quality for comprehensive molecular testing [15]. Furthermore, tumor heterogeneity may challenge small biopsies, particularly in metastatic disease with multiple tumors [16]. In contrast, the utility of plasma-derived circulating tumor DNA (ctDNA) has recently been assessed in several tumor types [17-21]. ctDNA has some advantages over tissue DNA analysis: (1) readily available, (2) less-invasive, (3) potential real-time monitoring of disease status or treatment response, and (4) may reflect shed DNA from multiple metastatic sites [2224]. On the other hand, the small amount of tumor DNA in the circulation results in limitations as well.

Herein, we assessed the genomic landscape of ctDNA in patients with PDAC, using clinical-grade nextgeneration sequencing (NGS). We investigated the clinical implications of the findings including concordance between tissue and blood DNA sequencing, relationship between ctDNA findings and survival, and potential as well as actual actionability, with the latter illustrated by a patient with multiple alterations affecting the MEK pathway whose tumor responded to the MEK inhibitor trametinib.

\section{Materials and methods}

\section{Study population}

We reviewed the clinicopathological and genomic information of 112 consecutive eligible patients with PDAC who had a blood-derived ctDNA evaluation. Only patients with pathologically proven PDAC were included. All investigations followed the guidelines of the University of California San Diego Moores Cancer Center Internal Review Board and were performed in accordance with the Declaration of Helsinki under the auspices of our approved study Profile-Related Evidence Determining Individualized Cancer Therapy study (PREDICT study, NCT02478931) and any investigational therapy for which the patients gave consent [25].

\section{Circulating tumor DNA (ctDNA) and tissue DNA sequencing ctDNA NGS}

All blood samples for ctDNA were evaluated at a clinical laboratory improvement amendments (CLIA) licensed and College of American Pathologist (CAP) accredited clinical laboratory, Guardant Health, Inc. (Redwood City, CA. http://www.guardanthealth.com). Blood samples were collected in $10 \mathrm{ml}$ Streck tubes, and 5 to $30 \mathrm{ng}$ of ctDNA was used for sequencing as previously described [26]. The ctDNA assay can sequence cancerassociated genes to identify somatic alterations with high analytic sensitivity, which reaches detection of 1-2 single mutant fragments from a $10-\mathrm{mL}$ blood sample $(0.1 \%$ limit of detection) and high specificity (> 99.9999\%) (54 to 73 genes, Additional file 1: Table S1). Only characterized genomic alterations were used for analysis (synonymous alterations or variants of unknown significance were excluded). Mutant allele frequency (\%ctDNA) was calculated as the number of mutant molecules divided by the total number of DNA fragments in each mutated gene. Percent ctDNA could not be calculated for gene amplifications. This study considered \%ctDNA for only characterized alterations and used median value as a cutoff for maximum \%ctDNA (of any alteration in a patient) or total \%ctDNA (evaluating all alterations per patient).

\section{Tissue DNA NGS}

All tissue DNA analyses in this study were performed by a CLIA-licensed and CAP-accredited laboratory, Foundation Medicine, Inc. (Cambridge, MA. https://www. foundationmedicine.com). The sequencing was designed to include all genes somatically altered in human solid malignancies that were validated as targets for therapy, either approved or in clinical trials, and/or that were unambiguous drivers of oncogenesis based on available knowledge. The assay interrogated 315 genes [27, 28].

\section{Actionable alterations in ctDNA}

This study assessed actionability for each genomic alteration in ctDNA. We defined a characterized alteration as potentially druggable if it (or its pathway signal) could be impacted at low inhibitory 
concentrations for small molecule inhibitors or if an antibody specific to the protein product of the alteration impacted it. Only cognate agents approved by the US. Food and Drug Administration (FDA) (on- or off-label use) or compounds that are currently in clinical trials were considered (Additional file 1: Table S2).

\section{Outcomes and statistics}

The continuous variables (described with median value and range) and categorical variables (described with frequency and percentage) were compared with the Mann-Whitney $U$ test and Fisher's exact test, respectively. In terms of ctDNA results according to disease stage, we compared metastatic, locally advanced, or recurrent (abbreviated as "advanced") disease setting with surgical resectable cases whose blood was biopsied before radical surgery. Concordance of genomic alterations between ctDNA and tissue DNA was assessed by concordance rate with Kappa value. Kappa value is interpreted by commonly used agreement categories: 1 (perfect agreement) to 0 (no agreement other than would be expected by chance). Most common gene aberrations (altered in $\geq 8$ samples) were used for concordance analysis. When patients were stratified according by tissue biopsy site or time interval between blood draw for ctDNA and tissue biopsy, the difference in concordance rate was compared by Fisher's exact test. OS time was measured from date of blood draw for ctDNA to date of last follow-up or all-cause death. In order to explore independent prognostic factors for the OS, we used Cox's proportional hazard model in multivariate analysis to estimate hazard ratio (HR) with 95\% confidence interval (CI). Variables with $P<0.1$ in the univariate analyses (using the logrank test) were entered into the multivariate analysis. $\mathrm{RO}$ performed and verified statistical analysis using SPSS version 24 software (IBM Corporation, Armonk, NY).

\section{Results}

Genomic alterations in ctDNA for PDAC

A total of 112 patients with PDAC were evaluated for ctDNA. Among them, 94 patients (84\%) were analyzed in the advanced setting, while 18 patients $(16 \%)$ were analyzed before $(N=10)$ or after radical surgery $(N=8)$ for lesions that were surgically resectable at the time of

Table 1 Patient characteristics and number of genomic alterations detected in ctDNA among pancreatic ductal adenocarcinoma patients $(N=112)$

\begin{tabular}{|c|c|c|c|}
\hline \multicolumn{2}{|l|}{ Characteristics for all patients $[N=112]$} & \multicolumn{2}{|l|}{$N(\%)$} \\
\hline \multicolumn{2}{|l|}{ Median age (range) (years)* } & \multicolumn{2}{|l|}{$67.8(38.0-92.7)$} \\
\hline \multicolumn{4}{|l|}{ Gender } \\
\hline \multicolumn{2}{|l|}{ Men } & \multicolumn{2}{|l|}{$60(53.6 \%)$} \\
\hline \multicolumn{2}{|l|}{ Women } & \multicolumn{2}{|l|}{$52(46.4 \%)$} \\
\hline \multicolumn{4}{|l|}{ Ethnicity } \\
\hline \multicolumn{2}{|l|}{ Caucasian } & \multicolumn{2}{|l|}{$76(67.9 \%)$} \\
\hline \multicolumn{2}{|l|}{ Hispanic } & \multicolumn{2}{|l|}{$16(14.3 \%)$} \\
\hline \multicolumn{2}{|l|}{ Asian } & \multicolumn{2}{|l|}{$7(6.3 \%)$} \\
\hline \multicolumn{2}{|l|}{ African American } & \multicolumn{2}{|l|}{$4(3.6 \%)$} \\
\hline \multicolumn{2}{|l|}{ Other/unknown } & \multicolumn{2}{|l|}{$9(8.0 \%)$} \\
\hline \multicolumn{4}{|l|}{ Disease status at the time of blood draw } \\
\hline \multicolumn{2}{|l|}{ Advanced (metastatic, locally advanced or recurrent disease) } & \multicolumn{2}{|l|}{$94(83.9 \%)$} \\
\hline \multicolumn{2}{|l|}{ Preoperative (surgically resectable, blood obtained before surgery) } & \multicolumn{2}{|l|}{$10(8.9 \%)$} \\
\hline \multicolumn{2}{|l|}{ Postoperative (surgically resectable, blood obtained after surgery) } & \multicolumn{2}{|l|}{$8(7.1 \%)$} \\
\hline \multicolumn{2}{|l|}{ Number of patients with $\geq 1$ characterized alteration } & \multicolumn{2}{|l|}{$78(69.6 \%)$} \\
\hline \multicolumn{2}{|l|}{ Median number of characterized alterations per patient (range) } & \multicolumn{2}{|l|}{$1(0-6)$} \\
\hline \multicolumn{4}{|l|}{ Comparisons of ctDNA results between advanced cases and preoperative cases** } \\
\hline Parameters & Advanced cases $(N=94)$ & Preoperative cases $(N=10)$ & $P$ value \\
\hline Number of characterized alterations per patient (range), median (range) (\%) & $2(0-6)$ & $0.5(0-3)$ & 0.04 \\
\hline No. of patients with detectable characterized alterations & $70(74.5 \%)$ & $5(50.0 \%)$ & 0.14 \\
\hline Maximum \%ctDNA per patient (characterized alterations), median (range) (\%) & $0.4(0.0-64.6)$ & $0.0(0.0-0.62)$ & 0.02 \\
\hline Total \%ctDNA per patient (characterized alterations), median (range) (\%) & $0.6(0.0-92.05)$ & $0.0(0.0-0.70)$ & 0.007 \\
\hline
\end{tabular}

*Age at date of advanced disease diagnosis or date of first diagnosis for surgically resectable diseases

**Postoperative cases (blood obtained after radical surgery) were not included in these comparisons 
blood draw for ctDNA (Table 1). Of the 112 patients, $70 \%(N=78)$ had $\geq 1$ characterized alteration in ctDNA, and the median number of characterized alterations per patient was 1 (range, 0 to 6). A total of 194 characterized alterations were identified, including 158 amino acid substitutions or frameshift mutations (81\%), 35 gene amplifications (18\%), and 1 gene deletion (0.5\%). These characterized alterations occurred in 29 different genes and included 112 distinct alterations. The most common genes altered were TP53 (46\% of patients, $N=51$ ), KRAS (44\%, $N=49), C D K N 2 A$ (7\%, $N=8)$, and GNAS (7\%, $N$ = 8) (Fig. 1).

\section{Most patients had ctDNA alterations that were potentially pharmacologically tractable}

Overall, 90\% of the characterized alterations (175/194) in ctDNA were potentially targetable with FDAapproved agents (on- or off-label use), and an additional $3 \%(6 / 194)$ were theoretically targetable with therapies that are currently in clinical trials (Additional file 1: Table S2). Meanwhile, 68\% $(N=76)$ of the 112 patients had $\geq 1$ theoretically actionable alterations by an FDAapproved agent (on- or off-label). Furthermore, among the 94 patients with advanced PDAC, $73 \%(N=69)$ had $\geq 1$ theoretically actionable alteration by FDA-approved agents (on- or off-label).
Patients with PDAC mostly had ctDNA portfolios that were distinct at the molecular level despite common alterations at the genomic level

Among the 78 patients who had $\geq 1$ characterized alteration, ID\#60 and ID\#88 (KRAS G12 V and KRAS amplification), ID\#24 and ID\#102 (TP53 V216 M), ID\#8 and ID\#85 (KRAS G12R), and ID\#64 and ID\#70 (KRAS G12 $\mathrm{V)}$ had molecularly identical portfolios in ctDNA. In addition, two patients harbored alterations in TP53, $K R A S$, and CDKN2A genes (ID\#7 and ID\#51), and 10 patients harbored alterations in TP53 and KRAS genes (ID\#3，ID\#14，ID\#31，ID\#74，ID\#76，ID\#87，ID\#95, ID\#96, ID\#101, and ID\#108), reflecting genomic portfolios that were identical but alterations at the level of the locus that were different (Additional file 1: Table S3).

\section{Patients with advanced PDAC had more ctDNA alterations} and higher \%ctDNA than those with surgically resectable disease

When evaluated depending on disease stage at the time of blood draw, median number of characterized alterations per patient was significantly higher in the patients with advanced PDAC $(N=94)$ than those with surgically resectable disease $(N=10)$ (the blood for ctDNA was biopsied before surgery) (2 versus $0.5, P=0.04$ ) (Table 1 ). Overall, $75 \%$ of patients with advanced PDAC had $\geq 1$ characterized alteration, compared with $50 \%$ of patients

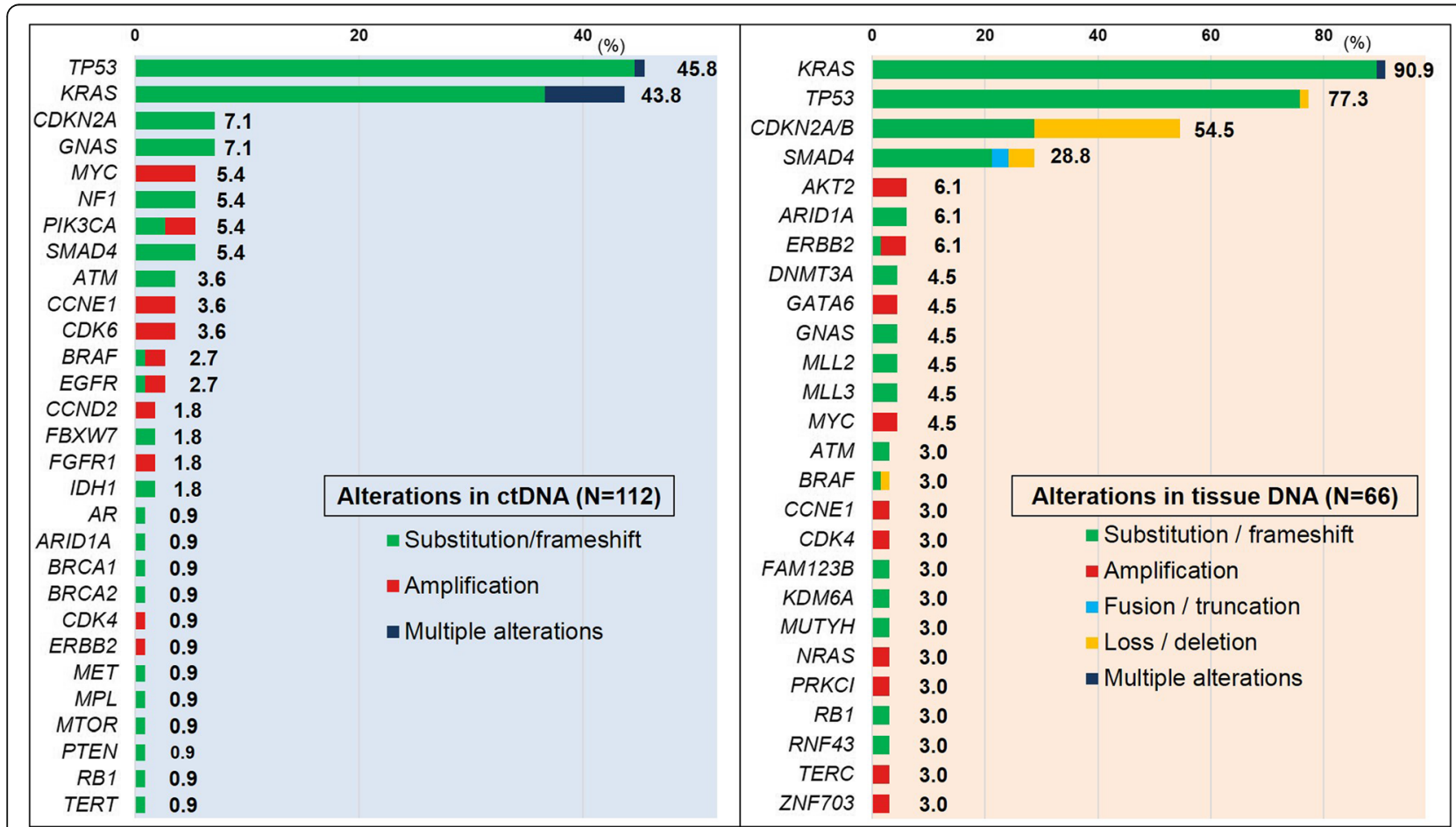

Fig. 1 Frequency (\% of patients) of characterized alterations in pancreatic ductal adenocarcinoma (ctDNA [N = 112] and tissue DNA [N = 66]). Only genes altered in $\geq 2$ patients were shown in tissue DNA 
with surgically resectable PDACs $(P=0.14)$. Moreover, the maximum \%ctDNA (among the characterized alterations) per patient was significantly higher in the patients with advanced PDAC than those with surgically resectable PDACs (median, 0.4 versus $0.0, P=0.02$ ), as well as the total \%ctDNA per patient (median, 0.6 versus $0.0, P=0.007)$. Complete list of ctDNA alterations and disease status at the time of ctDNA analysis for all the patients was shown in Additional file 1: Table S4. When comparing the ctDNA parameters according to disease stage at the time of ctDNA analysis among the $94 \mathrm{pa}-$ tients with advanced PDAC (between patients with $\geq 1$ treatment regimen prior to ctDNA test and chemotherapy naïve), no significant differences were observed (Additional file 1: Table S5).

\section{Concordance of altered genes between ctDNA and tissue DNA sequencing}

Of the 112 patients, 66 patients (59\%) also had tissue DNA NGS analysis (Additional file 1: Figure S1). In tissue DNA, alterations were commonly observed in KRAS, $(91 \%$ of the patients, $N=60)$, TP53 $(77 \%, N=51)$, and $C D K N 2 A / B(55 \%, N=36)$ (Fig. 1). Among the 66 patients, only four patients $(6.1 \%)$ had genomically concordant results between ctDNA and tissue DNA (Additional file 1: Table S6), and an additional 31 patients (47\%) had partially concordant results (having $\geq 1$ identical gene mutation) between the ctDNA and tissue sequencing.

Overall genomic concordance rate between ctDNA and tissue DNA analyses was $61 \%$ for TP53 and 52\% for KRAS (Table 2). Although the alteration rate in $C D K N 2 A$ was $7 \%$ ( $N=8$ of 112 samples) in ctDNA versus $55 \%(N=36$ of 66 samples) in tissue (Fig. 1), this discrepancy might be attributable to the fact that earlier versions of the ctDNA panel did not assess allelic loss in this gene; hence concordance rate was not assessable for the $C D K N 2 A$ gene.

\section{Spatial and temporal effects on concordance}

When compared according to tissue biopsy site (primary tumor versus metastatic sites), the concordance rate for KRAS was significantly higher between ctDNA and metastatic sites than between ctDNA and primary tumor (72\% versus $39 \%, P=0.01$ ); the difference for TP53 was not significant (Table 2). When compared according to the time interval between blood draw and tissue biopsy, the concordance rates for TP53 and KRAS genes were numerically higher in patients with $\leq 6$ months of time interval than those with $>6$ months $(55-65 \%$ versus $41-$ $47 \%$, but not statistically significant). Furthermore, consistent concordance rates for TP53 and KRAS alterations were observed among different ctDNA sequencing panels (when we compared detection rates for TP53 and $K R A S$ alterations according to ctDNA panel [73-gene panel, $N=41$, versus 54-70-gene panels, $N=25$ ], there were no significant differences $(P=0.61$ for TP53 and $P$ $>0.99$ for KRAS alterations).

\section{Overall survival from ctDNA analysis among patients with advanced PDAC}

\section{Higher levels of ctDNA were associated with shorter survival}

Survival analysis included 94 patients with advanced PDAC in whom the median follow-up time was 18.2 months (95\% CI, 13.7-22.7). In the univariate analysis, the presence of KRAS alterations in ctDNA and higher level of total \%ctDNA ( $\geq 0.6 \%$ [0.6\% being the median \%ctDNA when total ctDNA was assessed]) were associated with worse OS (Table 3 and Fig. 2). When the variables with $P$ value $<0.1$ were entered into the multivariate analysis, higher level of total \%ctDNA (HR 4.35, 95\% CI 1.8510.24) $(P=0.001)$ and $\geq 1$ systemic therapy prior to ctDNA analysis (HR 2.89, 95\% CI 1.51-5.55) $(P=0.001)$ were significantly associated with worse OS from ctDNA analysis in PDAC (OS from advanced disease diagnosis was also shorter in patients with higher level of total \%ctDNA) (Additional file 1: Figure S2). Even when the patients were stratified by ctDNA sequencing panel, there was no major difference between the 73-gene panel and the 54-70-gene panels (Additional file 1 Figure S3). Presence of KRAS or TP53 alteration in ctDNA was not significantly associated with OS in the multivariate analysis.

\section{ctDNA analysis and selection of targeted therapy}

Among the 94 patients with advanced PDAC, only 8 patients had treatment initiated based on the ctDNA results, and one of these patients responded (13\%). This patient was unusual in that he had three alterations in the MEK pathway (discussed below).

\section{Patient ID\#111}

An 83-year-old man with a locally advanced PDAC presented with abdominal and back pain (Eastern Cooperative Oncology Group Performance Status [ECOG-PS] = 2). His CT scan showed a pancreatic body tumor $(6.5 \times 3.2 \mathrm{~cm})$ spreading to the retroperitoneum and encasing the aorta and celiac artery and the dilation of the pancreatic duct. The biliary obstruction was not observed. Unfortunately, tissue biopsy of the pancreatic mass was insufficient for genomic analysis. However, his blood-derived ctDNA revealed EGFR G1022S, GNAS R201C, KRAS G12D, MTOR D258fs, and NF1 D1976fs. Because of the patient's age, he was hesitant to undergo chemotherapy. Based on the ctDNA analysis, he started the first-line treatment with trametinib (potentially targeting GNAS, KRAS, and NF1 alterations (Additional file 1: Table S2) [29-34]. He tolerated this treatment well and his pain significantly improved. Although his restaging CT 
Table 2 Overall concordance between ctDNA and tissue DNA based on time interval between blood draw and tissue biopsy and on whether primary or metastatic tumor was biopsied $(N=66)$

\begin{tabular}{|c|c|c|c|c|c|}
\hline \multicolumn{6}{|c|}{ Patients with pancreatic ductal adenocarcinoma who had both ctDNA and tissue DNA sequencing $(N=66)$} \\
\hline & & Tissue DNA (+) & Tissue DNA (-) & $\begin{array}{l}\text { Overall } \\
\text { concordance* }(\%)\end{array}$ & Kappa (SE) \\
\hline \multirow[t]{2}{*}{ TP53 } & $\begin{array}{l}\text { ctDNA } \\
(+)\end{array}$ & $29(44 \%)$ & $4(6.1 \%)$ & 61 & $0.21(0.1)$ \\
\hline & $\begin{array}{l}\text { ctDNA } \\
(-)\end{array}$ & $22(33 \%)$ & $11(17 \%)$ & & \\
\hline \multirow[t]{2}{*}{ KRAS } & $\begin{array}{l}\text { ctDNA } \\
(+)\end{array}$ & $28(42 \%)$ & $0(0.0 \%)$ & 52 & $0.14(0.1)$ \\
\hline & $\begin{array}{l}\text { ctDNA } \\
(-)\end{array}$ & $32(48 \%)$ & $6(9.1 \%)$ & & \\
\hline
\end{tabular}

Concordance depending on whether primary tumor or metastatic site was biopsied

\begin{tabular}{|c|c|c|c|c|c|c|c|c|c|c|}
\hline & & Primary tum & or $(n=41)$ & & & Metastatic sites & & & & \\
\hline & & $\begin{array}{l}\text { Tissue DNA } \\
(+)\end{array}$ & $\begin{array}{l}\text { Tissue DNA } \\
(-)\end{array}$ & $\begin{array}{l}\text { Overall } \\
\text { concordance* }(\%)\end{array}$ & $\begin{array}{l}\text { Kappa } \\
\text { (SE) }\end{array}$ & Tissue DNA (+) & $\begin{array}{l}\text { Tissue DNA } \\
(-)\end{array}$ & $\begin{array}{l}\text { Overall } \\
\text { concordance* }(\%)\end{array}$ & $\begin{array}{l}\text { Kappa } \\
\text { (SE) }\end{array}$ & $\begin{array}{l}P \\
\text { value }\end{array}$ \\
\hline TP53 & $\begin{array}{l}\text { ctDNA } \\
(+)\end{array}$ & $14(34 \%)$ & $1(2.4 \%)$ & 54 & $\begin{array}{l}0.19 \\
(0.1)\end{array}$ & 15 (60\%) & $3(12 \%)$ & 72 & $\begin{array}{l}0.27 \\
(0.2)\end{array}$ & 0.20 \\
\hline & $\begin{array}{l}\text { ctDNA } \\
(-)\end{array}$ & $18(44 \%)$ & $8(20 \%)$ & & & $4(16 \%)$ & $3(12 \%)$ & & & \\
\hline KRAS & $\begin{array}{l}\text { ctDNA } \\
(+)\end{array}$ & $14(34 \%)$ & $0(0.0 \%)$ & 39 & $\begin{array}{l}0.05 \\
(0.04)\end{array}$ & $14(56 \%)$ & $0(0.0 \%)$ & 72 & $\begin{array}{l}0.39 \\
(0.2)\end{array}$ & 0.01 \\
\hline & $\begin{array}{l}\text { ctDNA } \\
(-)\end{array}$ & $25(61 \%)$ & $2(4.9 \%)$ & & & $7(28 \%)$ & $4(16 \%)$ & & & \\
\hline
\end{tabular}

Concordance based on time interval between blood draw and tissue biopsy

\begin{tabular}{|c|c|c|c|c|c|c|c|c|c|c|}
\hline & & $\leq 6$ months & $(n=49)$ & & & $>6$ months $(n=$ & & & & \\
\hline & & $\begin{array}{l}\text { Tissue DNA } \\
(+)\end{array}$ & $\begin{array}{l}\text { Tissue DNA } \\
(-)\end{array}$ & $\begin{array}{l}\text { Overall } \\
\text { concordance* }(\%)\end{array}$ & $\begin{array}{l}\text { Kappa } \\
\text { (SE) }\end{array}$ & Tissue DNA (+) & $\begin{array}{l}\text { Tissue DNA } \\
(-)\end{array}$ & $\begin{array}{l}\text { Overall } \\
\text { concordance* (\%) }\end{array}$ & $\begin{array}{l}\text { Kappa } \\
\text { (SE) }\end{array}$ & $\begin{array}{l}P \\
\text { value }\end{array}$ \\
\hline TP53 & $\begin{array}{l}\text { ctDNA } \\
(+)\end{array}$ & $25(51 \%)$ & $3(6.1 \%)$ & 65 & $\begin{array}{l}0.24 \\
(0.1)\end{array}$ & $4(24 \%)$ & $1(5.9 \%)$ & 47 & $\begin{array}{l}0.10 \\
(0.2)\end{array}$ & 0.25 \\
\hline & $\begin{array}{l}\text { ctDNA } \\
(-)\end{array}$ & $14(29 \%)$ & $7(14 \%)$ & & & $8(47 \%)$ & $4(24 \%)$ & & & \\
\hline KRAS & $\begin{array}{l}\text { ctDNA } \\
(+)\end{array}$ & $22(45 \%)$ & $0(0.0 \%)$ & 55 & $\begin{array}{l}0.17 \\
(0.1)\end{array}$ & $6(35 \%)$ & $0(0.0 \%)$ & 41 & $\begin{array}{l}0.07 \\
(0.1)\end{array}$ & 0.40 \\
\hline & $\begin{array}{l}\text { ctDNA } \\
(-)\end{array}$ & $22(45 \%)$ & $5(10 \%)$ & & & $10(59 \%)$ & $1(6 \%)$ & & & \\
\hline
\end{tabular}

*Genomic concordance was analyzed in this table rather than molecular locus concordance

was not evaluable due to inability to use iodine contrast (underlying renal insufficiency), his PET-CT at 15 weeks showed only mild uptake in the primary tumor and CA19-9 demonstrated a remarkable decrease from 7272 to $1303 \mathrm{U} /$ $\mathrm{ml}$ (normal upper limit is $42 \mathrm{U} / \mathrm{ml}$ ) (Fig. 3). Serial ctDNA was analyzed at 19 weeks after the initiation of treatment and showed a decrease in \%ctDNA for NF1, and EGFR, GNAS, $K R A S$, and MTOR mutations were no longer detected (Fig. 3). The treatment continues at $26+$ weeks with good tolerance.

\section{Discussion}

Despite the recent development of aggressive chemotherapies, patients with pancreatic cancer, who are generally diagnosed with advanced stage disease, have a dismal outcome. Therefore, improvement in treatment strategies for this lethal malignancy based on a better understanding of its biology is urgently needed. Here, we investigated the landscape of ctDNA NGS in pancreatic cancer, its concordance with tissue DNA NGS, and the clinical implications of the findings.

We found that $70 \%$ of patients with PDAC had $\geq 1$ characterized genomic alteration in ctDNA (Table 1). Importantly, among the 94 patients with advanced PDAC, $73 \%(N=69)$ had $\geq 1$ theoretically actionable alteration by FDA-approved agents (on- or off-label) (Additional file 1: Table S2), opening the doors for precision matching trials [35-37]. These observations may be especially pertinent because several approved agents (such as gemcitabine and erlotinib) have only a small 
Table 3 Multivariate analysis for factors associated with overall survival from date of ctDNA analysis in patients with advanced PDAC $(N=94)$

\begin{tabular}{|c|c|c|c|c|}
\hline \multirow[t]{2}{*}{ Characteristics } & \multicolumn{2}{|l|}{ Univariate analysis } & \multicolumn{2}{|c|}{ Multivariate analysis* } \\
\hline & Median OS months & $P$ value & $\mathrm{HR}(95 \% \mathrm{Cl})$ & $P$ value \\
\hline \multicolumn{5}{|l|}{$\overline{\text { Age }}$} \\
\hline$\geq 68(N=47)$ vs $<68(N=47)$ & 11.5 vs 9.0 & 0.77 & - & - \\
\hline \multicolumn{5}{|l|}{ Gender } \\
\hline Men $(N=51)$ vs women $(N=43)$ & 9.9 vs 8.9 & 0.25 & - & - \\
\hline \multicolumn{5}{|l|}{ Genomic alterations in ctDNA } \\
\hline $\operatorname{KRAS}(N=48)$ vs not $(N=46)$ & 7.5 vs 11.4 & 0.03 & $1.14(0.53-2.45)$ & 0.74 \\
\hline $\operatorname{TP53}(N=45)$ vs not $(N=49)$ & 8.9 vs 10.1 & 0.67 & & \\
\hline \multicolumn{5}{|l|}{ Maximum \%ctDNA** } \\
\hline$\geq 0.4 \%(N=49)$ vs $<0.4 \%(N=45)$ & 8.9 vs 11.4 & 0.17 & - & - \\
\hline \multicolumn{5}{|l|}{ Total \%ctDNA** } \\
\hline$\geq 0.6 \%(N=50)$ vs $<0.6 \%(N=44)$ & 6.3 vs 11.7 & 0.001 & $4.35(1.85-10.24)$ & 0.001 \\
\hline \multicolumn{5}{|l|}{ Number of characterized alterations } \\
\hline$\geq 1(N=70)$ vs none $(N=24)$ & 8.9 vs 11.4 & 0.27 & - & - \\
\hline \multicolumn{5}{|c|}{ Number of systemic therapies prior to ctDNA analysis } \\
\hline$\geq 1$ regimen $(N=40)$ vs none $(N=54)$ & 6.4 vs 9.9 & 0.09 & $2.89(1.51-5.55)$ & 0.001 \\
\hline
\end{tabular}

Abbreviations: $C l$ confidence interval, ctDNA circulating tumor DNA, HR hazard ratio; \%ctDNA mutant allele frequency, OS overall survival

*Factors with $P$ value $<0.1$ in univariate analysis were included in the multivariate analysis

**Only characterized alterations were considered (synonymous alteration and VUS were excluded). Dichotomized at the median of $0.4 \%$ for the maximum $\% c t D N A$ and $0.6 \%$ for the total \%ctDNA

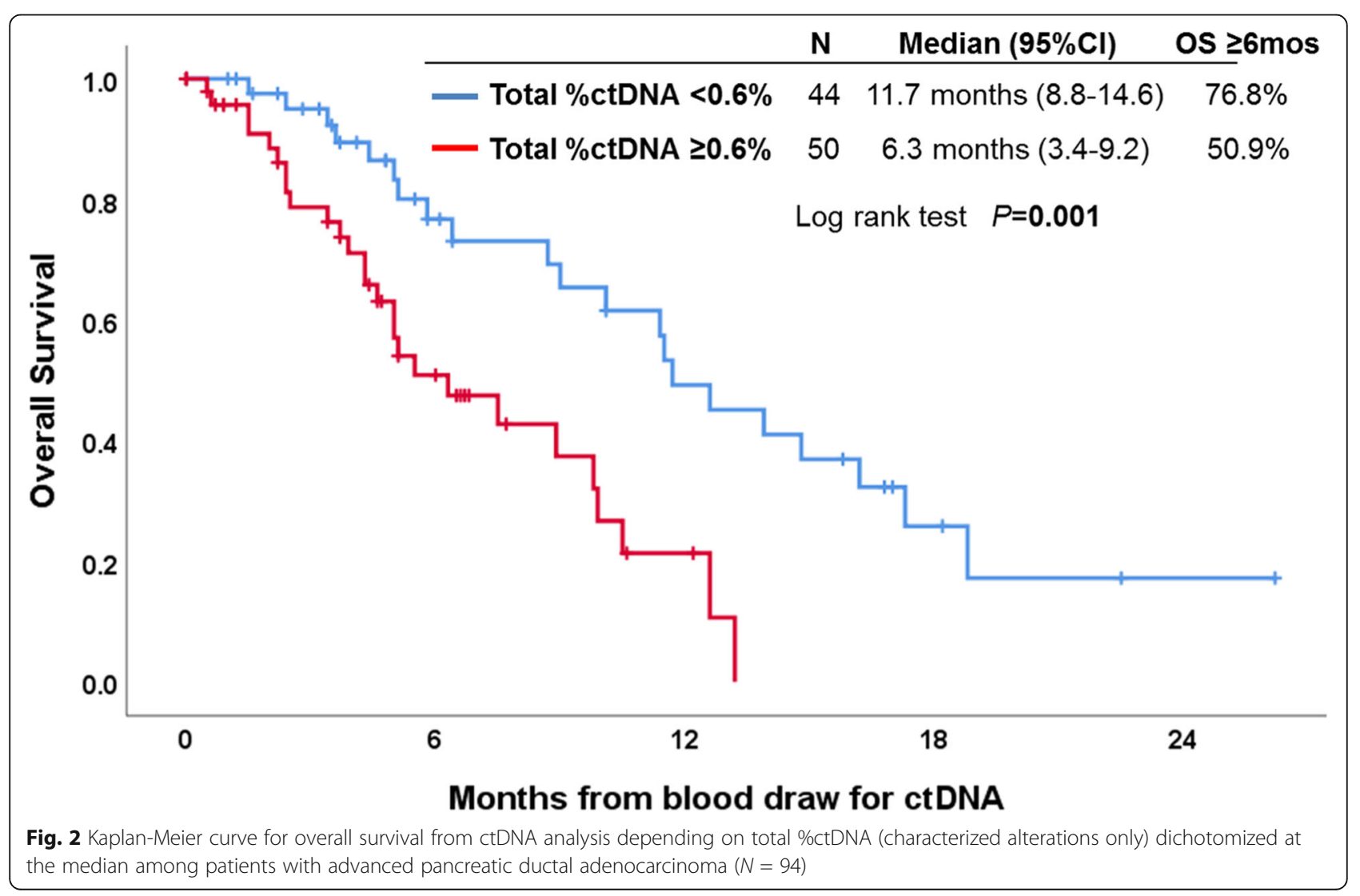




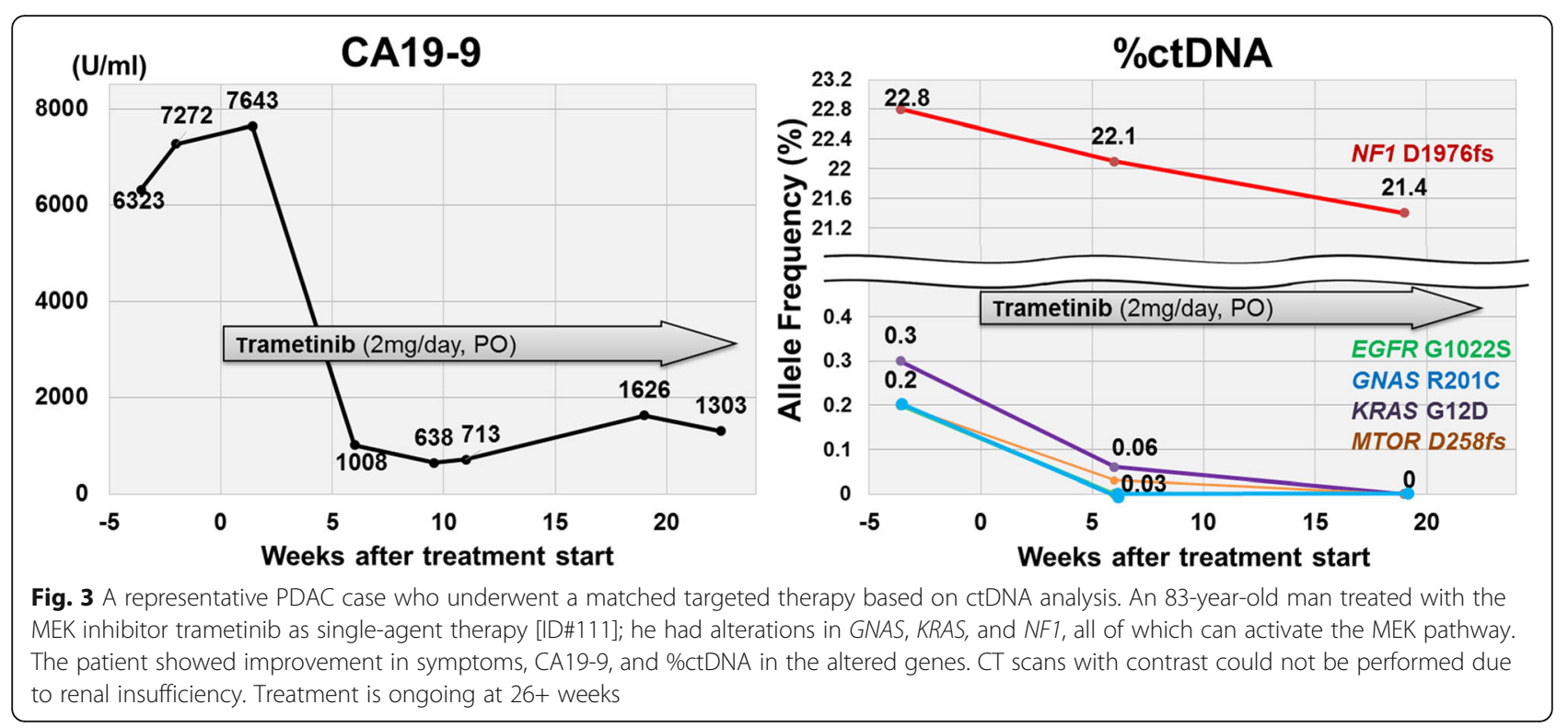

impact on survival [38]. The weak clinical impact may be due to lack of biomarker selection when prescribing treatment or existence of multiple oncogenic alterations. In fact, our data also showed that patients with advanced PDAC mostly had a unique pattern of molecular portfolios in ctDNA (even when the actual genomic alterations overlapped) and that more than half of them $(N=48 / 94)$ had two or more alterations, suggesting the need for a deep understanding of the effect of abnormalities in specific gene loci [39]. For instance, KRAS is well known as the dominant oncogene in pancreatic cancer and its prevalence is generally over $90 \%$ [40, 41]. Consistently, our data showed the prevalence of KRAS alterations was $91 \%$ in tissue DNA NGS (Fig. 1). Meanwhile, 9.1\% $(N=6 / 66)$ of patients with ctDNA and tissue DNA NGS had KRAS wild type in both of the two tests (Table 2). Several previous reports have suggested unique targetable alterations even in tumors with KRAS wild type, such as EGFR exon 19 deletion and $E R B B 2$ amplification [15, 42]. In our series, among the six patients whose ctDNA and tissue DNA NGS were both KRAS wild type, all had at least one theoretically actionable alteration in both the two tests, including EGFR amplification or $E R B B 2$ amplification.

Not unexpectedly, characterized alterations in ctDNA were more frequent in patients with advanced PDAC than in those with surgically resectable disease (median, 2 versus $0.5, P=0.04$ ); median of maximum \%ctDNA $(0.4 \%$ versus $0 \%, P=0.02)$ and median of total \%ctDNA $(0.6 \%$ versus $0 \%, P=0.007)$ were also higher (Table 1$)$. These findings are consistent with a previous report showing that ctDNA was more easily detectable in patients with metastatic cancer than those with localized diseases [43, 44]. Higher tumor load presumably increases ctDNA shedding to blood.

Overall concordance rate between ctDNA and tissue DNA was $61 \%$ for TP53 anomalies and 52\% for KRAS alterations (Table 2). In this series, the frequency of alterations in each gene was lower in ctDNA than in tissue DNA (Fig. 1). It should be noted that the sensitivity of ctDNA for tissue DNA in detecting alterations was lower, compared with that of tissue DNA for ctDNA (57\% [ 29 of 51] versus $88 \%$ [ 29 of 33] for TP53, and 47\% [28 of 60] versus $100 \%$ [28 of 28] for KRAS, respectively). Other studies have found similar results [45-47]. Discordant cases that were positive in tissue and negative in ctDNA have been previously explained by low tumor load in surgically resectable cases $[43,44]$. In addition, detection of ctDNA can be affected by systemic treatment prior to blood draw $[48,49]$. In terms of spatial effects on concordance, we demonstrated that KRAS concordance was significantly higher between ctDNA and metastatic sites than between ctDNA and primary tumor $(72 \%$ versus $39 \%, P$ $=0.01$ ) (Table 2). Consistent with our observations, a prior study evaluating heterogeneity in ctDNA genomic profiling results in gastroesophageal cancers also reported that several targetable genomic alterations were 88\% concordant between metastatic tissue and ctDNA even when primary tumor and metastatic sites had discordant results [23]. The authors suggested that biomarker profiling of metastatic site tissue or ctDNA was potentially more effective in selection of therapy than interrogating primary sites. In fact, in this series, ctDNA TP53 and KRAS alteration concordance rates in the patients whose tissues were biopsied from 
metastatic sites were numerically higher than the rates in the patients whose tissues were biopsied from primary tumors $(72 \%$ versus $54 \%$ for TP53, $P=0.20$; $72 \%$ versus $39 \%$ for KRAS, $P=0.01$ ) (Table 2). (The rate of tissue TP53 alterations was 76\% [19 of 25] for metastatic sites and 78\% [32 of 41] for primary sites; for KRAS alterations, it was $84 \%$ [ 21 of 25 ] versus $95 \%$ [39 of 41]; hence, there was no increased frequency of either alteration in tissue from metastatic sites.) It is conceivable that patients who have visible metastatic tumor that can be biopsied for sequencing may have higher tumor burden than those whose tissues for sequencing were available only from primary tumor, and this may explain the higher concordance rate with ctDNA. Further investigation is required [47, 50, 51]. Somewhat surprisingly, there was no statistically significant difference in concordance when ctDNA and tissue sampling dates were $\leq 6$ months versus $>6$ months apart. To further assess these spatial and temporal effects on concordance, larger numbers of samples are required.

We also report that the total \%ctDNA (dichotomized at median \%ctDNA) was associated with patient survival (median OS from blood draw for ctDNA, 6.3 versus 11.7 months, $P=0.001$; median OS from advanced disease diagnosis: 10.8 versus 18.2 months, $P=0.03$ ) (Fig. 2 and Additional file 1: Figure S2). Several studies previously reported that the presence of detectable ctDNA was associated with poor survival in pancreatic cancer $[52,53]$ or that the presence of KRAS alterations in ctDNA was a poor prognostic marker for OS in advanced PDAC [52, 54, 55]. In our series, multivariate analysis showed that $\geq 1$ prior therapy and higher total \%ctDNA, the latter perhaps reflecting greater tumor burden or shedding potential, were independently associated with worse OS (for higher total \%ctDNA, HR, 4.35; 95\%CI, 1.8510.24; multivariate $P=0.001$ ) (Table 3 ). Also, the presence of prior therapies (HR, 2.89; 95\%CI, 1.515.55; multivariate $P=0.001$ ) may reflect refractory cases who may have poorer prognosis.

To date, accumulating evidence has shown that matching drugs to sequenced genomic alterations can be promising for patients with advanced cancer [56-59]. However, we were only able to match eight patients to therapy based on ctDNA and only one (13\%) showed salutary effects (Fig. 3). The patient is unusual in several ways. In general, it is known that single targeted agents have limited effects in pancreatic cancer $[31,60,61]$. Tumor heterogeneity or the existence of coalterations may mediate resistance to scripted monotherapies [62]. However, our patient had multiple alterations that could activate the MEK pathway (GNAS R201C, KRAS G12D, and NF1 D1976fs) [29-33] and demonstrated a remarkable responsiveness to the MEK inhibitor trametinib, with a steep decline in CA19-9 and \%ctDNA as well as improvement in symptoms and PET imaging after therapy showing only minimal uptake in the tumor (Fig. 3). Our observation differs from previous literature suggesting that MEK inhibitors lack substantial anti-tumor activity among patients with pancreatic cancer $[31,63]$. The salutary effects in our patient might be due to the multiple MEK pathway abnormalities harbored by his cancer.

Meanwhile, low target-drug matching rate in this series $(8$ of 94 patients with advanced PDAC) is a realistic challenge. The remaining 55 patients received unmatched conventional chemotherapies following the molecular profiling and 31 had no systemic chemotherapies following the molecular profiling (mostly due to clinical deterioration or continuation of the regimen prior to the ctDNA test). Also, many patients with pancreatic cancer have genomic alterations that are not considered easily druggable. Therefore, to further investigate the efficacy of matched targeted therapy approaches, improvement in drug or clinical trial access as well as ctDNA testing in patients with less advanced disease will be necessary.

In the NCCN guidelines (https://www.nccn.org), testing for germline and somatic BRCA1/2 alterations is recommended for selection of platinum-based chemotherapies or PARP inhibitors based on emerging data from several small studies [11, 12, 64-66]. In our series, the prevalence of $B R C A 1 / 2$ abnormalities in ctDNA and tissue DNA NGS were $1.8 \%(N=2 / 112$; BRCA1 Splice Site SNV and BRCA2 T3033 fs $)$ and 3.0\% $(N=2 / 66 ; B R C A 1$ truncation intron 16 and BRCA2 A938fs*21), respectively (germline alterations were not captured). Several genomic alterations are rare and the number of patients who can benefit from targeting those individual abnormalities is small, but further study to investigate highly targetable biomarkers based on deep sequencing can be justified.

This study has several limitations. First, the ctDNA gene panel expanded with time, increasing from 54 to 73 genes (Additional file 1: Table S1). Therefore, a limitation of the study pertains to the fact that the sequencing panels were different and so not all genes sequenced in tissue were sequenced in ctDNA. Nonetheless, our tissue and ctDNA panels allowed the comparison of most of the commonly altered genes in pancreatic cancer using clinical-grade assays frequently utilized in patients. The discrepancy in the frequency of $C D K N 2 A / B$ loss between ctDNA and tissue (with lower frequency in ctDNA) probably results from the fact that its allelic loss was not captured in older panels of the ctDNA sequencing. Second, not all patients had both ctDNA and tissue DNA tests; therefore, future concordance analysis should be performed with larger numbers of patients. Moreover, further analysis with tissue DNA from both primary tissue and metastatic sites may help inform the issues related to intratumoral heterogeneity (though in many patients with pancreatic cancer, accessing biopsy sites can be challenging or dangerous). Third, analysis of the influence of systemic 
treatment on ctDNA alterations is not feasible in this study due to the lack of serial ctDNA testing per patient. Finally, additional studies are also needed to determine the impact of matching ctDNA alterations to therapy beyond the eight patients matched in the current investigation.

\section{Conclusions}

The majority of patients with PDAC (70\%) had at least one characterized genomic alteration and over $40 \%$ had TP53 or KRAS alterations in ctDNA (Table 1 and Fig. 1). Among patients with advanced PDAC, $73 \%$ had at least one alteration that is potentially pharmacologically tractable by FDAapproved agents. Patients with advanced PDAC had higher numbers of characterized alterations and higher maximum and total \%ctDNA when compared to those with surgically resectable diseases (Table 1). ctDNA results for KRAS mutations were significantly more concordant with tissue DNA when the biopsy was from a metastatic site (versus the primary site) (Table 2). Detection of higher levels of total \%ctDNA was an independent prognostic factor for poor overall survival (Fig. 2 and Table 3). A unique patient with three different alterations affecting the MEK pathway showed a sustained response to the MEK inhibitor trametinib, indicating that the nuances of how to best match patients to cognate agents merit further study in PDAC.

\section{Supplementary information}

Supplementary information accompanies this paper at https://doi.org/10. 1186/s13045-019-0824-4.

Additional file 1: Tables S1-S6 and Figures S1-S3 Supplementary tables and figures.

\begin{abstract}
Abbreviations
\%ctDNA: Mutant allele frequency; CAP: College of American Pathologist; Cl: Confidence interval; CLIA: Clinical laboratory improvement amendments; ctDNA: Circulating tumor DNA; ECOG-PS: Eastern Cooperative Oncology Group Performance Status; FDA: Food and Drug Administration of the United States; FOLFIRINOX: A combination of 5-fluorouracil, leucovorin, irinotecan, and oxaliplatin; HR: Hazard ratio; NGS: Next-generation sequencing; OS: Overall survival; PARP: Poly ADP-ribose polymerase; PDAC: Pancreatic ductal adenocarcinoma; PFS: Progression-free survival; PREDICT study: ProfileRelated Evidence Determining Individualized Cancer Therapy study
\end{abstract}

\section{Acknowledgements}

We thank Lee Suzanna, Rebecca E. Jimenez, David Philips-Moses, and Sophia C. Gumas for their critical roles in the PREDICT registry and data management

\section{Authors' contributions}

$\mathrm{RO}, \mathrm{HP}, \mathrm{SK}$, and RK contributed to the study conception and design. RO, HP, PF, and $\mathrm{CP}$ contributed to the data acquisition. RO and SK contributed to the statistical analysis. RO, SK, RBL, VMR, and RK contributed to the data interpretation. All authors participated in drafting the manuscript or revising it critically. All authors read and approved the final manuscript.

\section{Funding}

This study was funded by the Joan and Irwin Jacobs Fund and NIH P3O CA023100 (RK).

\section{Availability of data and materials}

The dataset used and analyzed during the current study are available from the corresponding author on reasonable request.

Ethics approval and consent to participate

All investigations followed the guidelines of UC San Diego Moores Cancer Center Internal Review Board and were performed in accordance with the Declaration of Helsinki under the auspices of our approved study (NCT02478931) and any investigational therapy. Written informed consent was obtained from each patient.

Consent for publication

Not applicable

\section{Competing interests}

RK has the following disclosure information: Leadership (CureMatch, Inc); Stock and Other Ownership Interests (IDbyDNA, CureMatch, Inc., and Soluventis); Consulting or Advisory Role (Gaido, LOXO, X-Biotech, Actuate Therapeutics, Roche, NeoMed, and Soluventis); Speaker's fee (Roche); Research Funding (Incyte, Genentech, Merck Serono, Pfizer, Sequenom, Foundation Medicine, Guardant Health, Grifols, Konica Minolta, and OmniSeq [All insts]). RBL has a leadership position at Guardant Health and RBL and VMR are employees and own stock at Guardant Health. The other authors have no competing interests to this work.

\section{Author details}

${ }^{1}$ Center for Personalized Cancer Therapy and Division of Hematology and Oncology, Department of Medicine, UC San Diego Moores Cancer Center, 3855 Health Sciences Drive, La Jolla, CA 92093, USA. ²Department of Pathology, UC San Diego, La Jolla, CA, USA. ${ }^{3}$ Department of Medical Affairs, Guardant Health, Inc., Redwood City, CA, USA.

Received: 29 July 2019 Accepted: 8 November 2019 Published online: 04 December 2019

References

1. Siegel RL, Miller KD, Jemal A. Cancer statistics, 2019. CA: a cancer journal for clinicians. 2019;69(1):7-34.

2. Rahib L, Smith BD, Aizenberg R, Rosenzweig AB, Fleshman JM, Matrisian LM. Projecting cancer incidence and deaths to 2030: the unexpected burden of thyroid, liver, and pancreas cancers in the United States. Cancer research. 2014;74(11):2913-21.

3. Ducreux M, Cuhna AS, Caramella C, Hollebecque A, Burtin P, Goere D, et al. Cancer of the pancreas: ESMO Clinical Practice Guidelines for diagnosis, treatment and follow-up. Annals of oncology : official journal of the European Society for Medical Oncology. 2015;26(Suppl 5):v56-68.

4. Ryan DP, Hong TS, Bardeesy N. Pancreatic adenocarcinoma. The New England journal of medicine. 2014;371(11):1039-49.

5. Oettle H, Neuhaus P, Hochhaus A, Hartmann JT, Gellert K, Ridwelski K, et al. Adjuvant chemotherapy with gemcitabine and long-term outcomes among patients with resected pancreatic cancer: the CONKO-001 randomized trial. Jama. 2013;310(14):1473-81.

6. Sinn M, Bahra M, Liersch T, Gellert K, Messmann H, Bechstein W, et al. CONKO-005: adjuvant chemotherapy with gemcitabine plus erlotinib versus gemcitabine alone in patients after $\mathrm{R} 0$ resection of pancreatic cancer: a multicenter randomized phase III trial. Journal of clinical oncology : official journal of the American Society of Clinical Oncology. 2017:35(29):3330-7.

7. Conroy T, Desseigne F, Ychou M, Bouche O, Guimbaud R, Becouarn Y, et al. FOLFIRINOX versus gemcitabine for metastatic pancreatic cancer. The New England journal of medicine. 2011;364(19):1817-25.

8. Von Hoff DD, Ervin T, Arena FP, Chiorean EG, Infante J, Moore M, et al. Increased survival in pancreatic cancer with nab-paclitaxel plus gemcitabine. The New England journal of medicine. 2013;369(18):1691-703.

9. Heestand GM, Kurzrock R. Molecular landscape of pancreatic cancer: implications for current clinical trials. Oncotarget. 2015;6(7):4553-61.

10. Blair AB, Groot VP, Gemenetzis G, Wei J, Cameron JL, Weiss MJ, et al. BRCA1/ BRCA2 germline mutation carriers and sporadic pancreatic ductal adenocarcinoma. Journal of the American College of Surgeons. 2018;226(4): 630-7.e1. 
11. Golan T, Kanji ZS, Epelbaum R, Devaud N, Dagan E, Holter S, et al. Overall survival and clinical characteristics of pancreatic cancer in BRCA mutation carriers. British journal of cancer. 2014;111(6):1132-8.

12. Waddell N, Pajic M, Patch AM, Chang DK, Kassahn KS, Bailey P, et al. Whole genomes redefine the mutational landscape of pancreatic cancer. Nature. 2015;518(7540):495-501.

13. Das S, Berlin J, Cardin D. Harnessing the immune system in pancreatic cancer. Current treatment options in oncology. 2018;19(10):48.

14. Lowery MA, Kelsen DP, Stadler ZK, Yu KH, Janjigian YY, Ludwig E, et al. An emerging entity: pancreatic adenocarcinoma associated with a known BRCA mutation: clinical descriptors, treatment implications, and future directions. The oncologist. 2011;16(10):1397-402.

15. Zill OA, Greene C, Sebisanovic D, Siew LM, Leng J, Vu M, et al. Cell-free DNA next-generation sequencing in pancreatobiliary carcinomas. Cancer discovery. 2015;5(10):1040-8

16. Swanton C. Intratumor heterogeneity: evolution through space and time. Cancer research. 2012;72(19):4875-82.

17. Kato S, Okamura R, Baumgartner JM, Patel H, Leichman L, Kelly K, et al. Analysis of circulating tumor DNA and clinical correlates in patients with esophageal, gastroesophageal junction, and gastric adenocarcinoma. Clinical cancer research : an official journal of the American Association for Cancer Research. 2018;24(24):6248-56.

18. Kato S, Krishnamurthy N, Banks KC, De P, Williams K, Williams C, et al. Utility of genomic analysis in circulating tumor DNA from patients with carcinoma of unknown primary. Cancer research. 2017;77(16):4238-46.

19. Schwaederle MC, Patel SP, Husain H, Ikeda M, Lanman RB, Banks KC, et al. Utility of genomic assessment of blood-derived circulating tumor DNA (ctDNA) in patients with advanced lung adenocarcinoma. Clinical cancer research : an official journal of the American Association for Cancer Research. 2017;23(17):5101-11.

20. Kato S, Okamura R, Mareboina M, Lee S, Goodman A, Patel SP, et al. Revisiting epidermal growth factor receptor (EGFR) amplification as a target for anti-EGFR therapy: analysis of cell-free circulating tumor DNA in patients with advanced malignancies. JCO precision oncology. 2019;3.

21. Kato S, Schwaederle MC, Fanta PT, Okamura R, Leichman L, Lippman SM, et al. Genomic assessment of blood-derived circulating tumor DNA in patients with colorectal cancers: correlation with tissue sequencing, therapeutic response, and survival. JCO precision oncology. 2019;3.

22. Russo M, Siravegna G, Blaszkowsky LS, Corti G, Crisafulli G, Ahronian LG, et al. Tumor heterogeneity and lesion-specific response to targeted therapy in colorectal cancer. Cancer discovery. 2016;6(2):147-53.

23. Pectasides E, Stachler MD, Derks S, Liu Y, Maron S, Islam M, et al. Genomic heterogeneity as a barrier to precision medicine in gastroesophageal adenocarcinoma. Cancer discovery. 2017.

24. Jamal-Hanjani M, Wilson GA, McGranahan N, Birkbak NJ, Watkins TBK, Veeriah S, et al. Tracking the evolution of non-small-cell lung cancer. The New England journal of medicine. 2017;376(22):2109-21.

25. Schwaederle M, Parker BA, Schwab RB, Daniels GA, Piccioni DE, Kesari S, et al. Precision oncology: The UC San Diego Moores Cancer Center PREDICT Experience. Molecular cancer therapeutics. 2016;15(4):743-52.

26. Lanman RB, Mortimer SA, Zill OA, Sebisanovic D, Lopez R, Blau S, et al. Analytical and clinical validation of a digital sequencing panel for quantitative, highly accurate evaluation of cell-free circulating tumor DNA. PloS one. 2015;10(10):e0140712.

27. Frampton GM, Fichtenholtz A, Otto GA, Wang K, Downing SR, He J, et al, Development and validation of a clinical cancer genomic profiling test based on massively parallel DNA sequencing. Nature biotechnology. 2013; 31(11):1023-31.

28. Thomas RK, Nickerson E, Simons JF, Janne PA, Tengs T, Yuza Y, et al. Sensitive mutation detection in heterogeneous cancer specimens by massively parallel picoliter reactor sequencing. Nature medicine. 2006;12(7): 852-5.

29. Cox AD, Fesik SW, Kimmelman AC, Luo J, Der CJ. Drugging the undruggable RAS: mission possible? Nature reviews Drug discovery. 2014; 13(11):828-51

30. Ideno N, Yamaguchi H, Ghosh B, Gupta S, Okumura T, Steffen DJ, et al GNAS(R201C) Induces pancreatic cystic neoplasms in mice that express activated kras by inhibiting yap1 signaling. Gastroenterology. 2018;155(5): 1593-607.e12

31. Infante JR, Somer BG, Park JO, Li CP, Scheulen ME, Kasubhai SM, et al. A randomised, double-blind, placebo-controlled trial of trametinib, an oral MEK inhibitor, in combination with gemcitabine for patients with untreated metastatic adenocarcinoma of the pancreas. European journal of cancer (Oxford, England: 1990). 2014;50(12):2072-81.

32. Lodish MB, Stratakis CA. Endocrine tumours in neurofibromatosis type 1, tuberous sclerosis and related syndromes. Best practice \& research Clinical endocrinology \& metabolism. 2010;24(3):439-49.

33. Hattori S, Ohmi N, Maekawa M, Hoshino M, Kawakita M, Nakamura S. Antibody against neurofibromatosis type 1 gene product reacts with a triton-insoluble GTPase activating protein toward ras p21. Biochemical and biophysical research communications. 1991;177(1):83-9.

34. Wilson $\mathrm{CH}$, Mclntyre RE, Arends MJ, Adams DJ. The activating mutation R201C in GNAS promotes intestinal tumourigenesis in Apc(Min/+) mice through activation of Wnt and ERK1/2 MAPK pathways. Oncogene. 2010; 29(32):4567-75.

35. Le Tourneau C, Kurzrock R. Targeted therapies: what have we learned from SHIVA? Nature reviews Clinical oncology. 2016;13(12):719-20.

36. Tsimberidou AM, Hong DS, Ye Y, Cartwright C, Wheler JJ, Falchook GS, et al. Initiative for Molecular Profiling and Advanced Cancer Therapy (IMPACT): an MD Anderson Precision Medicine Study. JCO precision oncology. 2017;2017.

37. Wheler JJ, Janku F, Naing A, Li Y, Stephen B, Zinner R, et al. Cancer therapy directed by comprehensive genomic profiling: a single center study. Cancer research. 2016;76(13):3690-701.

38. Moore MJ, Goldstein D, Hamm J, Figer A, Hecht JR, Gallinger S, et al. Erlotinib plus gemcitabine compared with gemcitabine alone in patients with advanced pancreatic cancer: a phase III trial of the National Cancer Institute of Canada Clinical Trials Group. Journal of clinical oncology : official journal of the American Society of Clinical Oncology. 2007;25(15):1960-6.

39. Sicklick JK, Leyland-Jones B, Kato S, Hahn M, Williams C, De P, et al. Personalized, molecularly matched combination therapies for treatment-na. 2017 ASCO Annual Meeting: abst 2512; 2017.

40. Jones S, Zhang X, Parsons DW, Lin JC, Leary RJ, Angenendt P, et al. Core signaling pathways in human pancreatic cancers revealed by global genomic analyses. Science (New York, NY). 2008;321(5897):1801-6.

41. Almoguera C, Shibata D, Forrester K, Martin J, Arnheim N, Perucho M. Most human carcinomas of the exocrine pancreas contain mutant c-K-ras genes. Cell. 1988;53(4):549-54.

42. Chou A, Waddell N, Cowley MJ, Gill AJ, Chang DK, Patch AM, et al. Clinical and molecular characterization of HER2 amplified-pancreatic cancer. Genome medicine. 2013;5(8):78.

43. Bettegowda C, Sausen M, Leary RJ, Kinde I, Wang Y, Agrawal N, et al. Detection of circulating tumor DNA in early- and late-stage human malignancies. Science translational medicine. 2014;6(224):224ra24.

44. Kruger S, Heinemann V, Ross C, Diehl F, Nagel D, Ormanns S, et al. Repeated mutKRAS ctDNA measurements represent a novel and promising tool for early response prediction and therapy monitoring in advanced pancreatic cancer. Annals of oncology : official journal of the European Society for Medical Oncology. 2018;29(12):2348-55.

45. Mardinian K, Okamura R, Kato S, Kurzrock R. Temporal and spatial effects and survival outcomes associated with concordance between tissue and blood KRAS alterations in the pan-cancer setting. International journal of cancer. 2019.

46. Chae YK, Davis AA, Jain S, Santa-Maria C, Flaum L, Beaubier N, et al. Concordance of genomic alterations by next-generation sequencing in tumor tissue versus circulating tumor DNA in breast cancer. Molecular cancer therapeutics. 2017;16(7):1412-20.

47. Schwaederle M, Husain H, Fanta PT, Piccioni DE, Kesari S, Schwab RB, et al. Use of liquid biopsies in clinical oncology: pilot experience in 168 patients. Clinical cancer research : an official journal of the American Association for Cancer Research. 2016;22(22):5497-505.

48. Del Re M, Tiseo M, Bordi P, D'Incecco A, Camerini A, Petrini I, et al. Contribution of KRAS mutations and c.2369C > T (p.T790 M) EGFR to acquired resistance to EGFR-TKIs in EGFR mutant NSCLC: a study on circulating tumor DNA. Oncotarget. 2017;8(8):13611-9.

49. Vidal J, Muinelo L, Dalmases A, Jones F, Edelstein D, Iglesias $M$, et al. Plasma ctDNA RAS mutation analysis for the diagnosis and treatment monitoring of metastatic colorectal cancer patients. Annals of oncology : official journal of the European Society for Medical Oncology. 2017;28(6):1325-32.

50. Kidess-Sigal E, Liu HE, Triboulet MM, Che J, Ramani VC, Visser BC, et al. Enumeration and targeted analysis of KRAS, BRAF and PIK3CA mutations in 
CTCs captured by a label-free platform: Comparison to ctDNA and tissue in metastatic colorectal cancer. Oncotarget. 2016;7(51):85349-64.

51. Dagogo-Jack I, Shaw AT. Tumour heterogeneity and resistance to cancer therapies. Nature reviews Clinical oncology. 2018;15(2):81-94.

52. Pietrasz D, Pecuchet N, Garlan F, Didelot A, Dubreuil O, Doat S, et al. Plasma circulating tumor DNA in pancreatic cancer patients is a prognostic marker. Clinical cancer research : an official journal of the American Association for Cancer Research. 2017;23(1):116-23.

53. Bernard V, Kim DU, San Lucas FA, Castillo J, Allenson K, Mulu FC, et al. Circulating nucleic acids are associated with outcomes of patients with pancreatic cancer. Gastroenterology. 2019;156(1):108-18.e4.

54. Chen H, Tu H, Meng ZQ, Chen Z, Wang P, Liu LM. K-ras mutational status predicts poor prognosis in unresectable pancreatic cancer. European journal of surgical oncology : the journal of the European Society of Surgical Oncology and the British Association of Surgical Oncology. 2010;36(7):657-62.

55. Earl J, Garcia-Nieto S, Martinez-Avila JC, Montans J, Sanjuanbenito A, RodriguezGarrote M, et al. Circulating tumor cells (Ctc) and kras mutant circulating free DNA (cfdna) detection in peripheral blood as biomarkers in patients diagnosed with exocrine pancreatic cancer. BMC cancer. 2015;15:797.

56. Schwaederle M, Zhao M, Lee JJ, Lazar V, Leyland-Jones B, Schilsky RL, et al. Association of biomarker-based treatment strategies with response rates and progression-free survival in refractory malignant neoplasms: a metaanalysis. JAMA oncology. 2016;2(11):1452-9.

57. Jardim DL, Schwaederle M, Wei C, Lee JJ, Hong DS, Eggermont AM, et al. Impact of a biomarker-based strategy on oncology drug development: a meta-analysis of clinical trials leading to FDA approval. Journal of the National Cancer Institute. 2015;107(11).

58. Schwaederle M, Zhao M, Lee JJ, Eggermont AM, Schilsky RL, Mendelsohn J, et al. Impact of precision medicine in diverse cancers: a meta-analysis of phase II clinical trials. Journal of clinical oncology : official journal of the American Society of Clinical Oncology. 2015;33(32):3817-25.

59. Sicklick JK, Kato S, Okamura R, Schwaederle M, Hahn ME, Williams CB, et al. Molecular profiling of cancer patients enables personalized combination therapy: the I-PREDICT study. Nature medicine. 2019.

60. Janne PA, van den Heuvel MM, Barlesi F, Cobo M, Mazieres J, Crino L, et al. Selumetinib plus docetaxel compared with docetaxel alone and progressionfree survival in patients with KRAS-mutant advanced non-small cell lung cancer: the SELECT-1 randomized clinical trial. Jama. 2017;317(18):1844-53.

61. Mangat PK, Halabi S, Bruinooge SS, Garrett-Mayer E, Alva A, Janeway KA, et al. Rationale and Design of the Targeted Agent and Profiling Utilization Registry (TAPUR) Study. JCO precision oncology. 2018;2018.

62. Farago AF, Piotrowska Z, Sequist LV. Unlocking the mystery of small-cell lung cancer transformations in EGFR mutant adenocarcinoma. Journal of clinical oncology : official journal of the American Society of Clinical Oncology. 2017;35(26):2987-8.

63. Chung V, McDonough S, Philip PA, Cardin D, Wang-Gillam A, Hui L, et al. Effect of selumetinib and MK-2206 vs oxaliplatin and fluorouracil in patients with metastatic pancreatic cancer after prior therapy: SWOG S1115 study randomized clinical trial. JAMA oncology. 2017;3(4):516-22.

64. Sonnenblick A, Kadouri L, Appelbaum L, Peretz T, Sagi M, Goldberg Y, et al. Complete remission, in BRCA2 mutation carrier with metastatic pancreatic adenocarcinoma, treated with cisplatin based therapy. Cancer biology \& therapy. 2011;12(3):165-8.

65. Luo G, Lu Y, Jin K, Cheng H, Guo M, Liu Z, et al. Pancreatic cancer: BRCA mutation and personalized treatment. Expert review of anticancer therapy. 2015;15(10):1223-31

66. Fogelman D, Sugar EA, Oliver G, Shah N, Klein A, Alewine C, et al. Family history as a marker of platinum sensitivity in pancreatic adenocarcinoma. Cancer chemotherapy and pharmacology. 2015;76(3):489-98.

\section{Publisher's Note}

Springer Nature remains neutral with regard to jurisdictional claims in published maps and institutional affiliations.

Ready to submit your research? Choose BMC and benefit from:

- fast, convenient online submission

- thorough peer review by experienced researchers in your field

- rapid publication on acceptance

- support for research data, including large and complex data types

- gold Open Access which fosters wider collaboration and increased citations

- maximum visibility for your research: over $100 \mathrm{M}$ website views per year

At $\mathrm{BMC}$, research is always in progress.

Learn more biomedcentral.com/submissions 